\title{
QUALIDADE INFORMACIONAL E CONSERVADORISMO NOS RESULTADOS CONTÁBEIS PUBLICADOS NO BRASIL
}

\author{
INFORMATION QUALITY AND CONSERVATISM \\ IN ACCOUNTING EARNINGS PUBLISHED IN BRAZIL
}

\author{
ANTONIO CARLOS COELHO \\ Professor Adjunto \\ do Departamento de Contabilidade \\ da Faculdade de Economia, Administraçăo, Contabilidad̦e, \\ Atuária e Secretariado dà Universidade Federal do Ceará - CE \\ E-mail: acarloscoelho@terra.com.br
}

\author{
IRAN SIQUEIRA LIMA \\ Professor Doutor do Departamento de Contabilidade e Atuária \\ da Faculdade de Economia, Administração e Contabilidade \\ da Universidade de São Paulo - Campus Capital \\ E-mail: julia.barker@fipecafi.org
}

\section{RESUMO}

O artigo avalia a presença de conservadorismo nos resultados apresentados nas demonstrações contábeis publicadas no Brasil pelas sociedades por ação no período de 1995 a 2004. Realiza-se a pesquisa em virtude da constatação de que a regulamentação brasileira, de um lado, é enfática no estabelecimento de princípio ou convenção do conservadorismo - antecipar o registro de perdas e diferir o reconhecimento de receitas - e, de outro, permite o reconhecimento prematuro de receitas não realizadas, como é o caso da reavaliação de ativos. $\mathrm{O}$ trabalho testou a antecipação oportuna assimétrica de perdas econômicas através do modelo de Componentes Transitốrios nos Lucros (BASU, 1997) e o conservadorismo condicional através do modelo de Associação entre Apropriações Contábeis e Fluxos de Caixa (BALL; SHIVAKUMAR, 2005). A amostra considera sociedades por ações com dados para a série temporal completa, regredindo-se os dados em painel segundo os métodos mais adequados. Os resultados confirmam a hipótese de que os gestores das empresas em questão não praticam o conservadorismo condicional, embora se constate reversão dos componentes transitórios do lucro em maior magnitude no caso de variações negativas do lucro antecedente.

Palavras-chave: Conservadorismo Condicional. Apropriaçôes Contábeis. Regulamentação Contábil: Qualidade informacional dos Lucros.

\section{ABSTRACT}

The article evaluates the practice of conservatism in the earnings presented in the accounting reports published in Brazil in the period from 1995 to 2004. The research is carried out in view of the fact that, on the one hand, Brazilian regulation emphatically establishes the principle or convention of conservatism - to anticipate the recording of losses and postponing the recognition of gains; on the other, it allows for the premature recognition of revenues not yet confirmed, like in the case of asset reevaluations. The research tested the asymmetrical timely anticipation of economic losses through the model of Basu (1997) and conditional conservatism through the model of association between accruals and cash flows (BALL; SHIVAKUMAR, 2005). The sample considers public and private companies with data for the complete time series, regressing panel data according to more adjusted methods. The results confirm the hypothesis that the managers of the sample companies do not adopt conditional conservatism, although evidences of greater reversal of transitory components of earnings are found in the case of negative variations in antecedent earnings.

Keywords: Conditional Conservatism. Accounting Accruals. Accounting Regulation. Earnings Quality. 


\section{INTRODUC̣ÃO}

As normas brasileiras de contabilidade, de um modo geral, não fazem qualquer referência explícita ao conservadorismo como conservadorismo condicional ou reconhecimento oportuno assimétrico de perdas econômicas.

Do ponto de vista genérico, a estrutura normativa da legislação contábil (Norma Legal, IBRACON, CFC, CVM) tende a ser conservadora, seja do ponto de vista patrimonial pela adoção do Custo Histórico como Base de Valor, seja na ótica dos resultados apurados pela aplicação da restrição da Prudência.

Contudo, existem particularidades normativas que conflitam com tal conceito, podendo-se citar a permissão de reavaliação de ativos, o diferimento da apropriação de gastos de instalação, a antecipação de ganhos a partir da norma de avaliação de instrumentos financeiros por 'marcação a mercado'.

Outras regras podem ser citadas de cunho conservador, como a que obriga o registro no presente de obrigações previdenciárias com fundos de pensão para empregados, bem como a antecipação de perdas no caso de avaliação de instrumentos financeiros.

O sentido conservador das normas está muito mais voltado para efetuar ajustes nos fluxos de caixa quanto ao confronto de receitas e despesas (Princípio da Realização de Receitas) e não o de antecipar prováveis perdas futuras avaliadas e estimadas a partir de eventos atuais.

Ao contrário, tal prática é desestimulada exceto por eventos cuja verificabilidade é mais patente como a provisão para devedores duvidosos e provisões para perdas em investimentos financeiros, inclusive recomendando apenas a evidenciação de alguns casos em notas explicativas.

Pela análise das normas de tributação, conclui-se por um ambiente neutro quanto à prática do conservadorismo, dada à vinculação do fenômeno contábil à apuração dos impostos corporativos, já que todas as formas (LALUR, lucro presumido, incentivos fiscais) têm suporte nos dados contábeis com normas rígidas de inclusão e exclusão de rubricas como tributáveis ou dedutíveis; contudo, a prática de reconhecimento assimétrico de perdas econômicas pode conduzir à antecipação de pagamento de impostos.

A verificação da existência da prática de conservadorismo contábil tem como marco a pesquisa de Basu (1997), na qual o autor associa o fenômeno ao registro antecipado assimétrico de perdas econômicas, detectando-se tal reconhecimento pela reversão dos componentes transitórios dos resultados negativos e pela persistência dos sinais quando da existência de resultados positivos.

Referido autor assinala que o conservadorismo na forma preconizada na regra contábil absoluta de antecipar perdas e diferir ganhos não possui conteúdo informacional, uma vez que sua aplicação apenas implicaria no desenho de curva de lucros linearmente transformada em níveis inferiores à original.

Ball e Shivakumar (2005) evoluem na detecção dessa prática desenvolvendo modelo que associa a antecipação tempestiva de perdas econômicas à existência de fluxos de caixa negativos contemporâneos; desse modo, a prática do conservadorismo estaria condicionada à existência de sinalização de mau desempenho econômico atual da empresa.

Os autores derivam, para tanto, funções econômicas das apropriações contábeis' em:

a) Ajustes temporais ao fluxo de caixa para atender aos princípios da realização da receita e da competência de exercícios;

b) Registro antecipado de perdas futuras prováveis, de modo a reduzir a assimetria informacional entre o gestor e os usuários da informação contábil.

O objetivo da pesquisa pode ser formulado do ponto de vista de investigar a presença nas demonstrações contábeis das sociedades por ações brasileiras da prática de conservadorismo e de examinar se tal presença estará condicionada à existência de signos que indiquem prováveis perdas futuras.

Para tanto foram consideradas as demonstrações contábeis das sociedades por ações que as encaminharam à SERASA e que continham dados completos para o período de 1995 a 2005, num total de 2.833 empresas; com base nessas informações, foram processados os modelos de Reversão de Componentes Transitórios no Lucro (BASU, 1997) e de Associação de Apropriações Contábeis com Fluxos de Caixa (BALL; SHIVAKUMAR, 2005).

A questão da pesquisa, então, pode ser formulada pela indagação seguinte: As sociedades por ações praticam o conservadorismo condicional na apuração dos lucros reportados nas demonstrações contábeis publicadas?

A hipótese que se adota no estudo é de que a prática de conservadorismo na apuração de resultados contábeis no Brasil não dependerá da existência de sinais de mau desempenho atual das firmas, implicando em que os lucros publicados têm fraca eficiência informacional.

O restante do artigo está, assim, estruturado: o capítulo 2 explana o referencial teórico no qual se baseia a investigação; em seguida, discute-se a metodologia aplicada, discorrendo-se sobre os modelos, os dados e a formulação da questão e da hipótese; no capítulo 4, são discutidos os resultados da investigação, apresentando-se as conclusões ao final do trabalho.

\footnotetext{
I ACCRUAL, que significa o ato de efetuar 'ajustes contábeis ao lucro advindos do regime de competência' (LOPES; MARTINS, 2005), será referido ao longo do texto pela expressão 'apropriações contábeis', que será utilizada com o significado de apropriar (tornar próprio) receita ou despesa ao resultado do período, cuja realização em caixa ocorre com defasagem temporal em relação ao momento do registro; esse procedimento trata-se da principal distinção entre o método contábil e outros instrumentos de registro e informação econômica.
} 


\section{REFERENCIAL TEÓRICO}

As normas brasileiras de contabilidade, de um modo geral, não fazem qualquer referência explícita ao conservadorismo como conservadorismo condicional ou reconhecimento oportuno assimétrico de perdas econômicas.

Tais regulamentos, consubstanciados nas Resoluções 750/93 e 774/94 do Conselho Federal de Contabilidade (CFC) - Princípios Fundamentais de Contabilidade - e na Deliberação 29/86 da Comissão de Valores Mobiliários (CVM) - Estrutura Conceitual Básica da Contabilidade (pronunciamento preparado pelo Instituto dos Auditores Independentes do Brasil \{IBRACON\}) - contêm expressa referência ao conceito de conservadorismo incondicional, da seguinte forma:

a) CFC: Princípio da Prudência que determina a adoção do menor valor para os componentes do ativo e do maior para os do passivo, sempre que se apresentem alternativas igualmente válidas para a quantificação;

b) CVM: Convenção (Restrição) do Conservadorismo (Prudência) que restringe a aplicação dos princípios fundamentais de contabilidade na avaliação do patrimônio; dentre conjuntos de avaliação igualmente válidos, escolhe-se a alternativa que apresente 0 menor valor atual para o ativo e o maior para as obrigações.

A aplicação direta dessas regras - o CFC ressalta que sua aplicação se dará em eventos subseqüentes ao primeiro registro - em conjunto com o Princípio do Custo Histórico como Base de Valor teria o efeito de reduzir, de forma absoluta, a avaliação do patrimônio líquido de todas as empresas. Vale dizer que sua eficiência informacional seria mínima, dado que, em qualquer circunstância econômica, todas as firmas reduziriam a avaliação de seu PL.

Obviamente, a utilização de tal regra somente se dá no registro de apropriações contábeis (antecipações e diferimentos) decorrentes de transações em que o fato gerador apenas se completa em mais de um período porquanto nos movimentos envolvendo caixa há a materialidade do evento e a determinação automática do valor da transação.

Portanto, associam-se essas regras à incerteza vinculada à finalização de operação em curso, tanto no que respeita a valores como no que tange a prazos e outras condições para sua realização. Dito de outro modo, o uso de apropriações contábeis com o propósito de confrontar receitas e despesas (Princípios da Competência e da Realização da Receita) deve ser feito com prudência quanto á incerteza dos valores a receber e a pagar e quanto à avaliação de sua contrapartida.

Quanto à função das apropriações contábeis de registrar tempestivamente alterações patrimoniais econômicas encontra-se referência no Princípio da Oportunidade (CFC - Princípios Fundamentais de Contabilidade) que preconiza o registro tempestivo e íntegro de alterações patrimo- niais, independente das causas que originaram, desde que estimáveis.

A interpretação autêntica desse preceito, contudo, tende a privilegiar a objetividade em detrimento da relevância, prevendo simetria no reconhecimento de impactos patrimoniais; do mesmo modo, a Convenção da Materialidade (CVM/IBRACON) destaca a imposição da regra custo/benefício quanto à discussão entre relevância da informação e objetividade na sua estimativa.

Desse modo, pode-se deduzir que a prudência - ou conservadorismo - preconizada diz respeito ao cálculo das probabilidades de ocorrência de resultados esperados em operações realizadas e não em associar, pelo reconhecimento contábil, aos resultados atuais o impacto de resultados futuros.

Entretanto, encontram-se, em outros normativos, referências que implicam, pragmaticamente, em orientações ao reconhecimento antecipado/oportuno de alterações patrimoniais de cunho econômico, ou seja, determinadas por alterações esperadas nos fluxos de caixa futuros associados a ativos e passivos da firma.

Podem ser destacadas as seguintes regras legais (Lei 6.404) que tocam na decisão de reconhecimento antecipado de ganhos e perdas, inclusive do ponto de vista de comparação internacional:

a) Aplicação mandatória da regra custo ou mercado, o menor para avaliação de ativos, o que implica, de um lado, em reconhecer a avaliação pela capitalização dos fluxos de caixa e, de outro, a aplicação do preceito do conservadorismo independente da avaliação das condições internas da empresa;

b) Permissão para reavaliação de ativos operacionais das firmas, sob condições de laudos técnicos e sensibilizando diretamente o patrimônio líquido, não afetando, portanto, os resultados do exercício; tal prática redunda em optar por superavaliação do patrimônio em contradição com os princípios já discutidos;

c) Diferimento indiscriminado de gastos incorridos e pagos, sob a alegativa de contribuição para o resultado de exercícios futuros, amortizados arbitrariamente, criando ativos sem valor econômico que não se apóia no conceito da alternativa mais conservadora;

d) Manutenção de receitas realizadas em grupo fora do patrimônio líquido reduzindo o possível reconhecimento dessas rendas antes de sua transformação em evento acabado;

e) Aplicação da avaliação por equivalência patrimonial de investimentos em coligadas e controladas, reconhecendo o caráter gerencial das demonstrações dessas últimas, incentivando, portanto, que se padronizem as práticas contábeis do ponto de vista de grupos econômicos, inclusive nos aspectos relacionados ao conservadorismo. 
Os objetivos das demonstrações contábeis, expressos nos diversos documentos de regulamentação da atividade contábil, declaram-se precipuamente a fornecer aos usuários da contabilidade informações necessárias ao procedimento da avaliação patrimonial da empresa.

Também se referem a fornecer apresentação correta do patrimônio e apreensão e análise das causas de suas mutações. A ênfase das normas dá-se no binômio tradicional da estrutura teórica da contabilidade baseada na mensuração dos fatos contábeis e na produção de informações para os públicos de interesse das firmas.

Tais normas são de teor diferente para as companhias abertas e para as companhias fechadas em virtude do grau de normatização praticado pela Comissão de Valores Mobiliários no que respeita às firmas que praticam captação de recursos de forma pública.

Essa capacidade decorre da conjunção dos poderes e determinações emanadas das Leis 6.385 e 6.404, que faz com que a CVM qualifique e expanda o significado básico da legislação societária. ${ }^{2}$

Dado que o objetivo dessa autarquia está completamente vinculado ao mercado de capitais, nota-se viés nas normas daí derivadas com o propósito de atender à relevância da informação para a avaliação das empresas cotadas em Bolsa. Isso conduz a uma busca de sua harmonização com práticas internacionais, sob o pretexto de dar acesso às companhias abertas brasileira a mercados internacionais de recursos.

A qualidade das demonstrações contábeis, por exemplo, é definida por essa autarquia como um atributo associado à obediência aos princípios e padrões normativos, no que segue a orientação de harmonização internacional, citando a norma do International Accounting Standards Board (IASB).

Quanto ao conservadorismo, pronuncia-se pela adoção de prudência na escolha da avaliação, propugnando pela neutralidade do contador o que significa a tendência a efetuar registros baseados em fatos objetivos e verificáveis, medindo custos e benefícios da decisão de informação adotada.

Em resumo, a CVM define como seu objetivo organizar normas contábeis em harmonia com os padrões internacionais, pressupondo que a regulamentação e a padronização melhoram a qualidade das demonstrações contábeis; nesse propósito, ressalta a relevância como atributo da informação contábil, estimulando que isso ocorra via evidenciação e não pelo reconhecimento que afete o patrimônio da empresa.

A conseqüência é que se tem uma contabilidade extremamente padronizada, quase cifrada em planos de contas (aliás, existentes para empresas do setor financeiro) com influência de normas emanadas do IASB e do FASB.

Ela está desarticulada em relação ao ambiente institucional da economia, em razão de sua rigidez determinada pela forma codificada do regime jurídico brasileiro e em função da concorrência de fontes privadas de fornecimento de informações aos usuários.

Não são demonstradas situações específicas a cada empresa, pois as normas estabelecem padronização excessiva, como seria esperado de contabilidade ligada em reportar com eficiência informacional a situação da empresa para seus usuários principais (LOPES; MARTINS, 2005).

Exemplos dessa postura podem ser evidenciados nos seguintes exemplos ${ }^{3}$, pelos quais se vê o interesse em estabelecer regras anódinas quanto ao registro de ganhos e perdas econômicas, resguardando a prudência na escolha das alternativas de avaliação:

a) Restrição ao uso de provisões para contingências menos prováveis, as quais são recomendadas a serem evidenciadas em notas explicativas;

b) Implantação da regra de marcação a mercado para ativos financeiros e derivativos, apurando o resultado das diferenças do custo para o valor de mercado dos títulos, seja ganho ou perda;

c) Incentivo a ativar créditos fiscais - respeitados alguns limites e condições - que implica em elevar receitas e ativos;

d) Apropriação de obrigações atuariais e outros benefícios de empregados, já incorridos e de realização a longo prazo;

e) Reconhecimento de goodwill apenas em transações de aquisição, fusão, incorporação e cisão, vinculadas, portanto, a valores objetivos da transação;

f) Preferência por evidenciação em notas explicativas de desvalorização de ativos associados a operações em descontinuidade, diferindo o registro de perdas para a realização dos prejuízos;

g) Regras em audiência pública para o reconhecimento de perdas associadas a ativos não recuperáveis bem como sua evidenciação em notas explicativas.

Na análise do conjunto de regras, constata-se tendência a dar transparência a fatos econômicos subjacentes à operação da empresa através da evidenciação; o reconhecimento de ganhos e perdas baseados em reavaliação dos fluxos de caixa esperados não está refletido claramente no conjunto das normas contábeis brasileiras.

As referências à prudência e ao conservadorismo estão associadas à escolha dos cálculos a serem realizados na determinação de valores e não na adoção de políticas diferenciadas na presença de sinais positivos ou negativos quanto ao desempenho da firma, fulcro maior da pesquisa sobre práticas diferenciadas na apreensão de tais efeitos econômicos nos registros contábeis.

Dessa maneira, o objetivo desses relatórios, em princípio, também está atrelado aos Princípios Fundamentais de Contabilidade (Resolução 774/94), qual seja o de mensurar corretamente e produzir dados para avaliação patrimonial.

2 Todas as normas e a legislação citadas nessa seção estão disponíveis em: <www.cvm.gov.br>. Acesso em: jun. 2006.

3 OFÍCIO-CIRCULAR/CVM/SNC/SEP № 01/2006, de 22 de fevereiro de 2006. Disponível em: <www.cvm.gov.br>. Acesso em: jun. 2006 
Os efeitos da legislação tributária nas práticas contábeis brasileiras também têm conseqüências em relação ao grau de conservadorismo de números patrimoniais $e$ de resultado. A questão é que a tributação da renda de pessoas jurídicas é baseada primordialmente nos agregados contábeis. A legislação arrecadatória classifica como renda tributável ou despesa dedutível todos os montantes lançados na contabilidade; criou o Livro de Apuração do Lucro Real (LALUR) em que são efetuados ajustes fiscais ao resultado contábil; contudo, tais ajustes restringem-se aos estabelecidos/permitidos pela autoridade fiscal e por legislação específica.

Diferentemente de práticas contábeis e fiscais existentes em países como a Inglaterra, não há a possibilidade de discrição entre o registro contábil com objetivos informacionais, econômicos ou contratuais e o registro de propósito explicitamente tributário.

No modelo brasileiro, há incentivo de prática de conservadorismo na apuração dos resultados através da antecipação do reconhecimento de perdas, uma vez que isso reduz o valor presente dos impostos a pagar ao longo do tempo.

Tal vinculação pode redundar em efeito contrário, eis que algumas perdas econômicas podem ter seu reconhecimento diferido simplesmente por serem dedutíveis apenas quando de sua realização ou de sua vinculação às receitas. Dado esse conflito, a formulação de hipótese específica sobre o efeito da legislação fiscal tende á imprecisão.

Em resumo, do ponto de vista genérico a estrutura normativa da legislação contábil (Norma Legal, IBRACON, CFC, CVM) tende a ser conservadora, seja do ponto de vista patrimonial pela adoção do Custo Histórico como Base de Valor, seja na ótica dos resultados apurados pela aplicação da restrição da Prudência.

Contudo, existem particularidades normativas que conflitam com tal conceito, podendo-se citar a permissão de reavaliação de ativos, o diferimento da apropriação de gastos de instalação, a antecipação de ganhos a partir da norma de avaliação de instrumentos financeiros por 'marcação a mercado'.

Outras regras podem ser citadas de cunho conservador, como a que obriga o registro no presente de obrigações previdenciárias com fundos de pensão para empregados, bem como a antecipação de perdas no caso de avaliação de instrumentos financeiros.

O sentido conservador das normas está muito mais voltado para efetuar ajustes nos fluxos de caixa quanto ao confronto de receitas e despesas (Princípio da Realização de Receitas) e não o de antecipar prováveis perdas futuras avaliadas e estimadas a partir de eventos atuais.

Ao contrário, tal prática é desestimulada exceto por eventos cuja verificabilidade é mais patente como a provisão para devedores duvidosos e provisões para perdas em investimentos financeiros, inclusive recomendando apenas a evidenciação de alguns casos em notas explicativas.

Pela análise das normas de tributação, conclui-se por um ambiente neutro quanto à prática do conservadorismo, dada a vinculação do fenômeno contábil à apuração dos impostos corporativos, já que todas as formas (LALUR, lucro presumido, incentivos fiscais) têm suporte nos dados contábeis com normas rígidas de inclusão e exclusão de rubricas como tributáveis ou dedutíveis; a prática de reconhecimento assimétrico de perdas econômicas pode conduzir à antecipação de pagamento de impostos.

De outra parte, apresentam-se pesquisas e ensaios que tratam de temas referentes ao conservadorismo e a apropriações contábeis no âmbito do Brasil.

Recente linha de pesquisa, com caráter eminentemente descritivo e exploratório (COLAUTO; BEUREN, 2005; COLAUTO et al. 2003), detecta correlação negativa entre o lucro líquido e as variações do capital circulante líquido, o que denota a função das apropriações contábeis (accruals accounting, na linguagem dos autores) de fazer o registro de eventos em que a ocorrência e a realização do caixa não são sincronizadas.

Em estudo de caso, os mesmos autores (COLAUTO; BEUREN, 2006) desenvolvem o exercício de segregar as apropriações contábeis das variações do capital circulante líquido de companhia aberta brasileira, sugerindo que os valores apropriados podem ser separados em elementos discricionários e não discricionários, não chegando a estabelecer separações entre eles.

Concluem os autores que o lucro contábil, além de resultante óbvio do somatório de itens positivos e negativos, traz em seu bojo conteúdo interpretativo e guardam informações relevantes para os mais variados usuários das informações contábeis.

Elementos discricionários e não discricionários na apuração do lucro são possíveis pela presença de apropriações contábeis como mecanismo utilizado pelos gestores, no reconhecimento de receitas e despesas, para disseminarem informações privadas para o mercado (LOPES, 200I).

Lopes (200I) continua analisando o conteúdo informacional dos dados contábeis para a precificação de ativos no Brasil. Utiliza como um dos fundamentos para o estudo a oportunidade do reconhecimento e a evidência de reconhecimento assimétrico de perdas como atributo requerido para que o dado contábil incorpore as informações contidas nos preços dos ativos.

Detecta um conservadorismo ao contrário praticado pelas companhias abertas brasileiras (amostra de 1995 a 1999), quando medido esse atributo pelo índice preço/ mercado, o qual, na média, se apresenta superior à unidade, o que significa que o conteúdo informacional dos preços das ações incorpora mais notícias negativas do que aquelas captadas pela contabilidade.

Comenta, então, que a prática contábil, em desacordo com as normas contábeis brasileiras e com o princípio (convenção) do conservadorismo não produz números conservadores para o patrimônio líquido das empresas no período estudado.

Por outro lado, identifica que as perdas econômicas não são reconhecidas oportunamente, mensurando tal reconhecimento pelo modelo de mercado de Basu (1997), 
encontrando coeficientes com significância estatística que não relacionam positivamente os lucros aos retornos nas observações que indicam desempenho negativo.

Os resultados podem mostrar que há incorporação de ganhos ao PL através da reavaliação de ativos e de outras práticas que não afetam os lucros publicados, mesmo porque não há confluência entre os coeficientes apresentados ano a ano; no geral, o autor assume que não se confirma a presença de conservadorismo nos números contábeis brasileiros.

O sentido dessa avaliação estava atrelado ao objetivo da pesquisa que buscava estudar a relevância do lucro contábil na avaliação de mercado das empresas através do emprego do modelo de Ohlson (1 995), pelo qual o valor da empresa é explicado pelo valor do patrimônio líquido mais o valor atual dos lucros anormais.

Nessa ordem de idéias, o conservadorismo - na forma mensurada e definida em Basu (1997) - representa importante atributo do lucro contábil, pois significa o oportuno reconhecimento de perdas econômicas nesse agregado; assim, a aplicação do modelo de Ohlson (1995) captaria efetivamente os lucros anormais incorporados ao retorno.

Costa et al. (2002) revisam a literatura sobre apropriações contábeis e qualidade do lucro, justificando que a diferença entre o fluxo de caixa e o lucro se dá exatamente por esses agregados, oriundos do Princípio do Regime de Competência.

Complementam o artigo com notícias de pesquisas que buscam relacionar essa prática com a qualidade do lucro, quando ela retrata conservadorismo e transmite informações privadas para o público.

Costa et al. (2002) tratam do assunto conservadorismo, realçando as diferenças entre o lucro contábil e o fluxo de caixa, provocadas pela presença de apropriações contábeis, em tentativa pioneira no Brasil de provocar estudos que utilizem dessa diferença no sentido de analisar a presença de conservadorismo nas demonstrações contábeis brasileiras.

Rangel e Teixeira (2003) analisam dados contábeis referentes ao período I 998/200 I relativos a empresas de capital aberto do setor de siderurgia e metalurgia, utilizando a comparação do índice "valor de mercado/valor contábil" para mensurar a prática de conservadorismo por tais empresas.

Suas conclusões são de que essas firmas não elaboram números contábeis com prudência, uma vez que o indicador comentado situa-se abaixo da unidade com significância estatística; tal situação ocorre mesmo retirando-se o efeito de reavaliações de ativos e despesando o total do ativo diferido.

Costa et al. (2006) aplicam o mesmo modelo de Basu (1997) para amostra de companhias abertas latino-americanas compreendendo o período de 1995 a 2001 para avaliar como o lucro contábil incorpora o retorno econômico nos países da amostra e como o conservadorismo vem sendo utilizado nesse processo de reconhecimento do retorno econômico pelo lucro contábil. Os resultados encontrados observam a baixa relação entre lucro corrente e retorno corrente, resultado esperado em países como os cinco estudados, qual seja a de países com regime de leis codificadas.

Corroborando a literatura recente, que indica que, nesses países, devido à relação entre modelos de governança corporativa e a relevância da informação contábil, em conjunto com o seu ambiente institucional, a contabilidade não incorpora significativamente o retorno econômico. Mesmo existindo essa baixa relação, pode-se observar que o reconhecimento dos resultados negativos é maior que o reconhecimento do retorno como um todo, evidenciando conservadorismo nos resultados contábeis.

Finalmente concluem esses autores que se observa, nesses países, que o principal foco da informação contábil não é o mercado de capitais, não significando que a informação contábil não seja relevante, posto que a contabilidade possua outros usuários e outros papéis.

Observam ainda que nos países em desenvolvimento, a contabilidade possui um importante papel de instrumento contratual entre as partes interessadas na empresa, quer seja entre acionistas, governo, credores e funcionários, diminuindo, dessa forma, conflitos e custo de transação.

Santos (2006) realiza estudo em que compara o grau de conservadorismo - mensurado na forma de Basu (1 997) - presente nos relatórios contábeis, entre 1999 e 2004, de empresas brasileiras negociadas nos mercados brasileiro e norte-americano, em suas versões publicadas seguindo os padrões dos US-GAAP e as regras dos BR-GAAP.

As hipóteses de maior presença de conservadorismo e de maior aderência entre retornos e lucros contábeis nos relatórios elaborados sob US-GAAP não se confirmam - implicitamente se depreende também que o grau de conservadorismo na amostra de empresas brasileiras não é elevado ou significante - concluindo o autor com explicações calcadas em governança corporativa para os resultados.

Mais recentemente, trabalho de Paulo et al. (2006) aplica o modelo de componentes transitórios do lucro, também de Basu (1997), para examinar grau de conservadorismo em empresas brasileiras, bem como diferenças de seu nível entre os grupos de companhias abertas e fechadas nesse particular. Nesse caso, o modelo utilizado é aquele complementado por Ball e Shivakumar (2005).

A análise dos dados, referente ao período 2000 a 2004 , forneceu evidências empíricas significativas estatisticamente de que os resultados positivos são componentes persistentes dos lucros.

Da mesma forma, pôde-se verificar que os resultados negativos são reconhecidos oportunamente, observandose, assim, um comportamento conservador nos números contábeis apresentados nas demonstrações financeiras, tanto para companhias fechadas quanto para as companhias abertas.

Concluem que os resultados obtidos permitem aceitar como válida a hipótese assumida na pesquisa, tendo em vista que as companhias fechadas apresentaram menor reconhecimento oportuno das perdas e, conseqüentemente, 


\begin{tabular}{|c|c|c|}
\hline Autor & Objetivo/Hipótese & Resultado \\
\hline LOPES (2001) & $\begin{array}{l}\text { Conservadorismo patrimonial e no } \\
\text { reconhecimento de perdas econômicas }\end{array}$ & $\begin{array}{l}\text { Detectado conservadorismo patrimonial ao } \\
\text { contrário e baixa antecipação de perdas }\end{array}$ \\
\hline COSTA; TEIXEIRA; NOSSA (2002) & $\begin{array}{l}\text { Revisão teórica e de pesquisas sobre } \\
\text { conservadorismo }\end{array}$ & Descrição teórica do assunto \\
\hline RANGEL; TEIXEIRA (2003) & $\begin{array}{l}\text { Detecção de conservadorismo através do } \\
\text { índice preço/PL }\end{array}$ & Baixo conservadorismo detectado \\
\hline COLAUTO; BEUREN; SOUSA (2003) & Correlação entre lucro e capital de giro & Detectada correlação negativa \\
\hline COLAUTO; BEUREN (2005) & Idem, idem & Idem, idem \\
\hline COLAUTO; BEUREN (2006) & $\begin{array}{l}\text { Estudo de caso sobre apropriações discri- } \\
\text { cionárias/ não discricionárias }\end{array}$ & $\begin{array}{l}\text { Constatada a existência dos dois tipos de } \\
\text { ajustamentos }\end{array}$ \\
\hline COSTA; LOPES; COSTA (2006) & $\begin{array}{l}\text { Conservadorismo entre países da América } \\
\text { do Sul }\end{array}$ & $\begin{array}{l}\text { Detectado baixo nível de conservadorismo } \\
\text { nos países pesquisados }\end{array}$ \\
\hline SANTOS (2006) & $\begin{array}{l}\text { Conservadorismo em sistemas contábeis } \\
\text { diferentes }\end{array}$ & $\begin{array}{l}\text { Sem diferença no conservadorismo sob } \\
\text { US-GAAP e BR-GAAP }\end{array}$ \\
\hline PAULO; ANTUNES; FORMIGONI (2006) & $\begin{array}{l}\text { Distinção da prática de conservadorismo } \\
\text { entre empresas de capital aberto e de } \\
\text { capital fechado }\end{array}$ & $\begin{array}{l}\text { Maior conservadorismo apresentado nas } \\
\text { empresas de capital aberto }\end{array}$ \\
\hline
\end{tabular}

Quadro 1

\section{Pesquisas Brasileiras sobre Conservadorismo e Apropriações Contábeis}

possuem menor nível de conservadorismo nas demonstrações contábeis em relação ao das companhias abertas.

Avaliando os resultados acima a respeito da realidade contábil brasileira, nota-se que o último modelo apresenta conclusões mais definidas, trazendo indícios de que a presença de tal atributo não está relacionada ao significado dos dados contábeis para a avaliação das firmas no mercado de capitais, sendo intrínseco ao ambiente institucional e contratual brasileiros.

Apresenta-se, na ilustração seguinte, sinopse das pesquisas brasileiras realizadas sobre o tema genérico da qualidade dos lucros reportados no Brasil.

A presença do conservadorismo condicional será mensurada, através de dois modelos básicos, desenvolvidos e testados originalmente em Basu ( 1 997) e Ball e Shivakumar (2005).

A primeira relação modela a apropriação contábil tempestiva assimétrica de perdas econômicas pelo grau e pelo sinal de associação entre variações do lucro no período atual e variações do lucro no período anterior, segmentada segundo o sinal - positivo ou negativo - dessa última variação; expresso na forma de regressão, tem-se o Modelo 8 abaixo

As variáveis são expressas escaladas pelo ativo total do final do período anterior àquele da própria variável, no sentido de reduzir a grandeza numérica da sua variabilidade e são captadas para cada empresa e cada período da amostra.

O Modelo I será aplicado utilizando-se dos seguintes agregados para o resultado contábil:

a) Lucro Líquido (disponível para distribuição entre participações estatutárias e acionistas);

b) Lucro Operacional (na forma definida pela legislação brasileira, somando-se, portanto, ao lucro líquido, os itens não operacionais e os impostos diretos); c) Lucro Abrangente (calculado pela variação limpa do patrimônio líquido no período respectivo).

Valem-se desses diversos agregados com o propósito de mensurar possíveis efeitos específicos das rubricas contábeis diferenciadoras dos diversos conceitos sobre o objeto da pesquisa. A ocorrência de conservadorismo decorrente de questões tributárias ou associadas a itens não operacionais pode ser detectada pela disparidade entre os coeficientes associados aos dois conceitos.

$$
\begin{gathered}
\Delta L U C_{t}=\alpha_{0}+\alpha_{1} D \Delta L U C_{t-1}+\alpha_{2} \Delta L U C_{t-1}+ \\
+\alpha_{3} D \Delta L U C_{t-1} * \Delta L U C_{t-1}+\varepsilon_{t}
\end{gathered}
$$

Onde:

$\Delta L U C_{t}=$ Variação do lucro no período t;

$\Delta L U C_{t-1}=$ Variação do lucro no período $\mathrm{t}-1$;

$D \Delta L U C_{t}=$ Variável binária assumindo 1 para variações negativas e 0 para variações positivas do lucro no período $\mathrm{t}-1$;

$D \Delta L U C_{t-1} * \Delta L U C_{t-1}=$ Variável discriminatória de variações negativas do lucro no período $\mathrm{t}-1$;

$\alpha_{1} ; \alpha_{2} ; \alpha_{3}=$ Coeficientes do modelo; $\varepsilon_{t}=$ Termos dos resíduos do modelo

Modelo 1 Modelo de Componentes Transitórios nos Lucros

A avaliação pelo Lucro Abrangente atende à intenção de examinar o efeito de apropriações contábeis que não transitam pelo resultado do exercício, como a reavaliação de ativos ou o reconhecimento de ativos pelo valor de mercado em casos previstos na legislação. 
Esse modelo se fundamenta na formulação enunciada em Basu (1997) de que a antecipação assimétrica de perdas econômicas está associada à existência prévia de sinais de desempenho negativo da firma; essa sinalização abrevia o lapso de tempo para que os gestores antecipem o registro de perdas porventura daí decorrente.

O segundo modelo também segrega as variáveis segundo seu sinal positivo e negativo representando o conservadorismo condicional pela correlação contemporânea entre o montante do fluxo de caixa operacional da firma em dado período e o valor das apropriações contábeis lançadas naquele mesmo período; econometricamente se tem a seguinte função:

$$
\begin{aligned}
& A C_{t}=\beta_{0}+\beta_{1} D F C O_{t}+\beta_{2} F C O_{t}+\beta_{3} D F C O_{t} * F C O_{t}+v_{t} \\
& \text { Onde: } \\
& A C_{t}=\text { Apropriações Contábeis no período t; } \\
& F C O_{t}=\text { Fluxo de Caixa Operacional no período t; } \\
& D F C O_{t}=\text { Variável binária assumindo } 1 \text { para }
\end{aligned}
$$

Modelo 2 Modelo de Associação entre Apropriações Contábeis e Fluxos de Caixa

As observações serão tomadas para cada empresa e para cada período da amostra e também terão suas medidas de variabilidade reduzidas porque serão escaladas pelo montante do ativo total do final do período anterior.

As variáveis aplicadas, nesse modelo, são calculadas pelas fórmulas de cálculo seguintes, valendo destacar que o conceito foi expandido em forma alternativa de apreensão do capital de giro, incluindo-se rubricas transitórias operacionais (principalmente relacionadas a impostos diferidos e créditos tributários) registradas nos grupos realizáveis e exigíveis a longo prazo - idiossincrasia associada à composição do balanço patrimonial no Brasil.

$$
\begin{array}{r}
A C \\
\text { Onde: }
\end{array}
$$

$$
A C_{t}=\left(\Delta A C_{t}-\Delta A F_{t}\right)-\left(\Delta P C_{t}-\Delta P F_{t}\right)-D_{t}
$$

$$
A C_{t}=\text { Apropriações Contábeis no período t; }
$$

$\left(\Delta A C_{t}-\Delta A F_{t}\right)=$ Incremento dos Ativos Circulantes Operacionais no período $t$;

$\left(\Delta P C_{t}-\Delta P F_{t}\right)=$ Incremento dos Passivos Circulantes Operacionais no período t;

$D_{t}=$ Depreciação contabilizada no período t.

Cálculo de Ajustes Contábeis em razão do Princípio da Competência Contábil

O Modelo 2 está fundamentado na idéia desenvolvida em Ball e Shivakumar (2005) de que, havendo sinalização de baixa performance atual pela existência de fluxos de caixa negativos, os gestores apropriarão de imediato o valor presente das futuras perdas prováveis associadas a esse evento atual; ao contrário, com sinalização de boa performance atual não se capitalizam ganhos possíveis no futuro daí decorrentes.

Os dois modelos pressupõem que a sinalização das perdas atuais torna a possibilidade de perdas econômicas mais facilmente verificável do que a sinalização de ganhos atuais para garantir que ocorrerão ganhos futuros. Tal verificabilidade está associada a custos de estimação bem assim a custos de transação associados a litígios de investidores e a agentes oportunistas ou maximizadores de sua utilidade.

$$
F C O_{t}=L O_{t}-D_{t}-I D_{t}-\Delta C G_{t}-R \tilde{N}_{t}
$$

Onde:

$\mathrm{FCO}_{t}=$ Fluxo de Caixa Operacional no período $\mathrm{t}$;

$L O_{t}=$ Lucro Operacional no período t;

$I D_{t}=$ Impostos diretos despesados no período $\mathrm{t}$;

$\Delta C G_{t}=$ Variação do Capital de Giro Operacional no período t;

$R \tilde{N}_{t}=$ Resultado não Operacional no período t.

Cálculo do Fluxo de Caixa Operacional

\section{METODOLOGIA}

O objetivo da pesquisa concentra-se em realizar testes que captem o grau de conservadorismo contido nos lucros publicados pelas sociedades por ação brasileiras, dado que as normas contábeis vigentes recomendam tal prática explicitamente, embora normas subalternas estabeleçam regras que se contrapõem a essa prática.

Os testes são efetuados no pressuposto de que o conservadorismo somente pode ser mensurado de forma condicional, de tal modo que a antecipação de registros sobre eventos futuros será efetuada de forma assimétrica, reconhecendo-se apenas as perdas econômicas previstas.
Assim, no caso de conservadorismo, espera-se que a associação entre as variações dos lucros atuais confrontadas com as variações negativas dos lucros antecedentes será negativa e que a correlação entre apropriações contábeis e fluxos de caixa contemporâneos negativos será positiva.

Os testes buscam responder à seguinte questão: As sociedades por ações brasileiras praticam o conservadorismo condicional na apuração dos lucros reportados nas demonstrações contábeis publicadas?

Efetua-se a investigação considerando a seguinte hipótese nula: $\mathrm{H}_{0}$ : As sociedades por ação brasileiras não 
praticam o conservadorismo condicional na apuração dos lucros publicados.

Isso implica em que os coeficientes relativos a variações negativas do lucro antecedente terão sinal positivo (modelo I) e aqueles coeficientes referentes a fluxos de caixa negativos terão sinal negativo (modelo 2 ).

Para estimar os coeficientes de associação dos dois modelos, utilizou-se análise de dados em painel. Foi usado o método que combina todos os dados em corte transversal e em séries temporais para estimar o modelo usando mínimos quadrados ordinários. Esse modelo é considerado adequado quando a amostra é composta de firmas diferentes (GUJARATI, 2006).

Ademais, foi testada a influência de variáveis não observáveis, seja por efeitos fixos, seja por efeitos aleatórios, usando-se para a análise final a relação estatística mais adequada.

O caráter hipotético-dedutivo da pesquisa evidenciase, pois as hipóteses apresentadas serão testadas estatisticamente em regressões englobando dados globais, para se deduzir sobre o comportamento individualizado dos gestores de empresas consideradas na amostra.

Os dados primários para a pesquisa foram coletados nas Demonstrações Contábeis entregues por empresas sediadas no Brasil à SERASA S.A., que é uma reconhecida empresa brasileira no ramo do gerenciamento de bancos de dados e informações para análises de balanço e para decisões de crédito e apoio a negócios; ademais, administra o maior banco de dados do Brasil derivados de informações contábeis públicas e privadas.

O banco de dados continha informações anuais, referentes ao período disponível naquela organização de 1989 a 2004 e relativas a 20.092 unidades societárias, com as seguintes carências:

Como a entrega de demonstrações contábeis para a SERASA é voluntária, pode-se dizer que a amostra utilizada apresenta viés para empresas que busquem endividamento bancário - já que essa organização fornece análise de crédito para instituições bancárias e outros fornecedores; que estejam conectadas com atividades urbanas e de melhor comunicação; e que se disponham a assumir o custo de preparação e remessa de tais relatórios.

Assim, a população para a pesquisa pode ser definida como empresas organizadas como sociedades por ação; a população-alvo vai se restringir àquelas que entregaram relatórios contábeis à SERASA; a amostra final ficou definida de forma dirigida, pois foram utilizadas apenas as empresas para as quais se dispunham da série completa de demonstrações contábeis de 1993 a 2004.

A análise foi efetuada para o período de 1995 a 2004. sendo necessária a consideração de dois anos a menos, dada a característica defasada de cálculo de alguns dos dados; ademais, o processamento de séries mais longas ( I 99I a 2004) não acrescenta maior significância ou poder explanatório aos modelos, muito provavelmente em virtude da alteração estrutural que se processou, em 1 994, com o Plano Real na economia brasileira.

A série completa torna-se necessária porque uma das variáveis relevantes para a análise é a variação de lucros, que implica em basear-se em série temporal de dados, além da característica requerida por dados balanceados em painel de séries completas repetindo-se as mesmas observações no tempo, no caso, empresas.

Para se coletarem dados em painel, devem ser observados os mesmos indivíduos, empresas ou cidades ao longo do tempo. Essa mesma amostra é investigada novamente em muitos pontos subseqüentes no tempo. E tal procedimento, que fornece dados do mesmo grupo em diferentes períodos, foi o adotado no estabelecimento da amostra final.

A composição da amostra completa final está demonstrada na Tabela I $\boldsymbol{O}$, em que se apresenta sua composição em termos geográficos, setoriais e de origem do controle, ficando estabelecida sua abrangência quanto a esses quesitos.

Tabela 1 Composição da Amostra

\begin{tabular}{l|r|r}
\multicolumn{3}{c}{ Origem do Controle } \\
Estatal & 95 & $3,3 \%$ \\
\hline Privado Estrangeiro & 189 & $6,7 \%$ \\
\hline Privado Nacional & 2.549 & $90,0 \%$ \\
\hline Distribuição Geográfica & 88 & $3,1 \%$ \\
\hline Norte & 382 & $13,5 \%$ \\
\hline Nordeste & 97 & $3,4 \%$ \\
\hline Centro-Oeste & 1527 & $53,9 \%$ \\
\hline Sudeste & 728 & $25,7 \%$ \\
\hline Sul & 11 & $0,4 \%$ \\
\hline Sem Indicação da Sede & 11 & $0,4 \%$ \\
\hline Distribuição Setorial & 458 & $16,2 \%$ \\
\hline Administração Pública & 158 & $5,6 \%$ \\
\hline Comércio & 44 & $1,6 \%$ \\
\hline Construção & 431 & $15,2 \%$ \\
\hline Serviços Públicos & 37 & $1,3 \%$ \\
\hline Imobiliário & 1240 & $43,8 \%$ \\
\hline Indústria Extrativa & 17 & $0,6 \%$ \\
\hline Indústria de Transformação & 159 & $5,6 \%$ \\
\hline Intermediários Financeiros & 104 & $3,7 \%$ \\
\hline Logística & 174 & $6,1 \%$ \\
\hline Setor de Serviços & 2833 \\
\hline Agricultura, Pecuária, Pesca & \\
\hline Total da Amostra &
\end{tabular}

\section{ANÁLISE DOS RESULTADOS}

A análise dá-se sobre as medidas de reconhecimento tempestivo assimétrico de perdas pela reversão de compo- nentes transitórios no lucro e pela associação entre apropriações contábeis e fluxos de caixa operacionais atuais, 
examinando se os lucros contábeis são reportados conservadoramente apenas nos casos em que os resultados atuais indicam perspectiva de resultados futuros rebaixados.

A Tabela 20 demonstra os resultados do Modelo I, o qual mensura os graus de reversão ou de continuidade do nível de lucro ao longo do tempo, dado o sinal das variações ocorridas no lucro antecedente. São examinados tais efeitos em três diferentes conceitos de lucro: Lucro Líquido, Lucro Operacional e Lucro Abrangente.

De início, destaque-se que o modelo apresenta poder explanatório reduzido ( $\mathrm{R}^{2}$ ajustado variando de 4,02\% a $6,32 \%$ ) dando conta, portanto, de baixa correlação entre a série temporal dos lucros das companhias, provavelmente decorrente da grande variância observada na série de resultados contábeis analisada.

O parâmetro $\alpha_{2}$ indica a associação entre as variações antecedentes positivas no lucro e as variações atuais e pondera a persistência do lucro após a presença de variações positivas; na hipótese aqui desenvolvida espera-se que sua correlação seja positiva, isto é, que não haja reversão do comportamento do lucro.

Entretanto, esse parâmetro varia de $-0,05$ a $-0,08$ nos três conceitos de lucro, com significância estatística; indica que as empresas brasileiras não diferem o reconhecimento de ganhos econômicos até sua realização, o que sugere a apropriação de ganhos que não persistem nos anos posteriores.

O coeficiente $\alpha_{3}$ mede o diferencial no coeficiente de associação entre as variações antecedentes positivas e as variações atuais e entre as variações antecedentes negativas e as variações atuais do lucro. Denota diferenças na persistência dos componentes do lucro nos dois casos. Tal parâmetro, estatisticamente significante, se mostra negativo, inferindo-se que a reversão dos lucros é de maior magnitude quando há variações negativas no lucro.

O parâmetro varia de - 0, 15 (lucro operacional) a - 0,27 (lucro abrangente), indicando uma maior diferenciação nos coeficientes nesse último conceito de lucro. Guardada a cautela pelos dados disponíveis para o cálculo desse último conceito, tal resultado surpreende pela presença no Brasil da permissão para efetuar reavaliações nos ativos imobilizados, contabilizados diretamente contra o PL.

Constata-se, então, que reduções do PL são contabilizadas sem que transitem pelo resultado do exercício nem provenham de relações da empresa com os acionistas. Uma possibilidade seria por conta de movimentos de registro associados ao goodwill nas operações de aquisição/fusão/ incorporação.

A soma dos coeficientes $\alpha_{2}$ e $\alpha_{3}$ detecta a relação entre variações no lucro antecedentes negativas e variações atuais no lucro. Seu sinal negativo indica que há reversão na trajetória do lucro nos períodos seguintes, provavelmente decorrente de apropriações antecipadas de perdas econômicas pelo seu valor capitalizado em dado exercício.

A variação negativa decorre da redução do lucro pela antecipação de perdas econômicas e a variação nula ou positiva subseqüente implica em que não foi realizado outro movimento de contabilização de perdas, o que não ocasiona persistência no nível de lucros da firma.

O resultado $\alpha_{2}+\alpha_{3}$ apresenta sinal negativo nos vários conceitos de lucro a nível significante, sendo bem menor que - I (coeficiente em que a reversão estaria ligada somente às perdas lançadas apenas uma vez); essa situação limite não é factível, pois não se pretende que o único efeito para reversão das variações de lucro decorra de antecipação de perdas econômicas.

A soma dos coeficientes (que varia de - 20\% a - 35\%) significa que há reversão do sentido do lucro ao longo do período pesquisado, inferindo-se sobre a antecipação, com maior rapidez, do registro de maus resultados em confronto com a rapidez com que são antecipados os registros de ganhos econômicos.

Vale mencionar a expressiva diferença entre os parâmetros do lucro líquido e do lucro abrangente em relação ao do lucro operacional, dando a entender que a prática do conservadorismo se daria através de movimentos de baixa de ativos contra resultados não operacionais em processos de impairment ou pela apropriação antecipada de impostos diferidos.

Detecta-se a reversão de cerca de 30\% de reduções ocorridas nos lucros das firmas brasileiras, o que é consistente com reconhecimento tempestivo assimétrico de perdas econômicas. Também há reversão de cerca de 5\% dos incrementos ocorridos nesses lucros, assinalando reconhecimento antecipado de ganhos econômicos.

Não há persistência no nível de lucro tanto após experimentar um aumento quanto uma redução no lucro antecedente e esses comportamentos não são consistentes com o reconhecimento tempestivo assimétrico.

Tabela 2 Resultado da Regressão Componentes Transitórios nos Lucros

\begin{tabular}{l|c|c|c|c|c|c|c|c|c}
\multirow{2}{*}{ Coeficientes } & \multicolumn{4}{|c|}{ Lucro Líquido } & \multicolumn{3}{c|}{ Lucro Operacional } & \multicolumn{2}{c}{ Lucro Abrangente } \\
\cline { 2 - 11 } & Valor & Teste t & Sig. & Valor & Teste t & Sig. & Valor & Teste t & Sig. \\
\hline$\alpha_{1}$ & -0.00 & -0.49 & 0.62 & 0.00 & -0.58 & 0.56 & -0.02 & 0.01 & -3.67 \\
\hline$\alpha_{2}$ & 0.01 & 1.77 & 0.08 & 0.02 & 3.64 & 0.00 & 0.04 & 3.13 & 0.00 \\
\hline$\alpha_{3}$ & -0.07 & -3.14 & 0.00 & -0.05 & -3.33 & 0.00 & -0.08 & -7.31 & 0.00 \\
\hline$\alpha_{2}+\alpha_{3}$ & -0.24 & -3.45 & 0.00 & -0.15 & -2.77 & 0.00 & -0.27 & -4.04 & 0.00 \\
\hline $\mathrm{R}^{2}$ ajustado & \multicolumn{3}{|c|}{-0.31} & & -0.20 & & -0.35 \\
\hline
\end{tabular}


Pode-se aceitar a hipótese da pesquisa pelo modelo sob comentário, não sendo conclusiva, contudo, a rejeição da hipótese alternativa de correlação negativa apenas nos casos de variações negativas dos lucros precedentes, além de se registrar que o modelo apresentou baixo poder explanatório, com significância estatística em todos os coeficientes relevantes.

Considerando que essa formulação não contém elementos identificadores da origem dos componentes transitórios (erros aleatórios ou práticas de gerenciamento de resultados) ou determinantes do componente que ocasionou a reversão (anterior ou posterior ao fato gerador), aplica-se o modelo seguinte (BALL; SHIVAKUMAR, 2005).

A avaliação de práticas de conservadorismo condicional é feita pela aplicação do Modelo 2, que confronta as apropriações contábeis com o fluxo de caixa, cujos resultados estão condensados na Tabela 3, a qual contempla dois conceitos de captação dos efeitos das apropriações contábeis (o de capital de giro circulante e outro que adiciona as contas de realizável e exigível a longo prazo).

Supõe-se que as apropriações contábeis têm função diversa em razão da sinalização fornecida pelo fluxo de caixa no período; se essa é positiva, espera-se que os ajustes tenham sido feitos para compensar o efeito do caixa antecipado ou diferido; se o sinal do fluxo é negativo, admite-se que os ajustes por competência foram feitos para antecipar os efeitos futuros atribuíveis por estimativa ao mau desempenho atual.

$\mathrm{Na}$ primeira situação, espera-se relação negativa (de compensação) entre as duas variáveis; no segundo papel, a relação esperada entre essas é positiva (complementar), na hipótese de se estar praticando o conservadorismo condicional, qual seja antecipando registro de perdas econômicas se há indicativos pelo fluxo de caixa de sua provável ocorrência futura.

A expectativa é de que esse efeito seja dominante pela magnitude dos valores (se antecipa como despesa o valor capitalizado do projeto) em comparação com os valores de compensação que também ocorrem com os fluxos de caixa negativos.
A formulação considerando os itens patrimoniais de longo prazo não carece de análise detalhada uma vez que seu $\mathrm{R}^{2}$ ajustado é insignificante, o que equivale a dizer que as apropriações contábeis geradoras de ativos e passivos de longo prazo no Brasil não se caracterizam por ajustes que introduzam aspectos de conservadorismo ao resultado divulgado.

Já a avaliação do modelo que utiliza apenas o conceito de capital de giro não conduz à refutação da hipótese da pesquisa de ausência de conservadorismo condicional nos resultados publicados pelas firmas brasileiras, com o modelo apresentando satisfatório poder explanatório $\left(R^{2}\right.$ ajustado $=47,78 \%$ )

O parâmetro $\alpha_{2}$ mostra-se consistente (Sig. = 0,07) com o papel de compensação das apropriações contábeis para fluxos de caixa positivos, pois denota associação negativa entre essas variáveis, ou seja, na ocorrência de fluxos de caixa positivos são efetuadas apropriações redutoras nesses valores da ordem de $17 \%$, a fim de se produzirem séries temporais de lucros mais suavizadas em relação ao descompasso entre saídas e entradas de caixa.

Já o coeficiente $\alpha_{3}$, em conformidade com a hipótese, apresenta-se negativo (- 57\%), com significância estatística, indicando que nos casos em que ocorrem fluxos de caixa negativos também ocorrem compensações através de apropriações contábeis.

Tal compensação é da ordem de $74 \%\left(\alpha_{2}+\alpha_{3}\right)$, resultado que não suporta a rejeição da hipótese nula. Em outras palavras, não se detecta, na realidade brasileira aqui enfocada, a utilização de apropriações contábeis no sentido de produzir informações acerca de prováveis perdas econômicas.

Os pressupostos econométricos dos modelos são satisfeitos quanto à correlação serial dos resíduos (DW 2), quanto à heterocedasticidade, após homogeneização da variância dos resíduos pela correção de White; já a normalidade da distribuição dos resíduos é satisfatória para as conclusões em razão do tamanho da amostra. Os efeitos de variáveis não observáveis estão controlados, com a variância sendo explicada por efeitos aleatórios em mudanças temporais.

Tabela 3 | Resultado da Regressão Apropriações Contábeis

\begin{tabular}{l|c|c|c|c|c|c}
\multirow{2}{*}{ Coeficientes } & \multicolumn{3}{|c|}{ Circulante } & \multicolumn{3}{c}{ Circulante + Longo Prazo } \\
\cline { 2 - 7 } Intercepto & Valor & Teste t & Sig. & Valor & Teste t & Sig. \\
\hline$\alpha_{1}$ & -0.02 & -1.88 & 0.06 & -0.00 & -0.11 & 0.91 \\
\hline$\alpha_{2}$ & 0.02 & 1.14 & 0.25 & 0.05 & 3.73 & 0.00 \\
\hline$\alpha_{3}$ & -0.17 & -1.81 & 0.07 & 0.06 & 0.93 & 0.35 \\
\hline$\alpha_{2}+\alpha_{3}$ & -0.57 & -4.80 & 0.00 & -0.04 & -0.35 & 0.72 \\
\hline R2 ajustado & \multicolumn{3}{|c|}{-0.74} & \multicolumn{3}{c}{0.02} \\
\hline
\end{tabular}




\section{CONCLUSÕES}

Os resultados empíricos levam a inferir que o atributo do conservadorismo condicional não é encontrável nos resultados contábeis pesquisados; por decorrência, infere-se que os agentes econômicos não demandam tal atributo nas informações contábeis produzidas pelas firmas brasileiras em seu total.

A oferta da informação contábil - caracterizada essencialmente pela propriedade dos ajustes em função da competência contábil - não se preocupa em informar aos usuários sobre a existência de prováveis perdas econômicas tempestivamente.

Ademais, os resultados podem ser atribuídos ao caráter contraditório das normas contábeis brasileiras sobre o assunto, conforme já destacado acima; tal contradição aparece tanto na Lei 6.404 como em regulamentações realizadas por autarquias competentes.

\section{Referências}

BALL, R. J.; SHIVAKUMAR, L. Earnings quality in UK private firms: comparative loss recognition timeliness. Journal of Accounting and Economics, Amsterdam, v. 39, p. 83-128, 2005.

BASU, S: The conservatism principle and the asymmetric timeliness of earnings. Journal of Accounting and Economics, Amsterdam, v. 24, n. 1 , p. 3-37, 1997.

COLAUTO, R. D.; BEUREN, I. M.; SOUSA, M. A: B. Um estudo sobre a influência de accruals na correlação entre o lucro contábil e a variação do capital circulante líquido de empresas. In: XXVII EnANPAD, 2003, Atibaia-SP. Anais... Curitiba: Associação Nacional dos Programas de Administração (ANPAD), 2003, CD-ROM:

; BEUREN, I. M. Análise empírica dos impactos dos accruals na:variação do capital circulante líquido: um estudo no setor de siderurgia e metalurgia. In: CONGRESSO USP DE CONTROLADORIA E CONTABILIDADE,V, 2005, São Paulo. Anais... São Paulo: 2005 , CD-ROM

BEUREN, I. M. A identificação de accruals na sintaxe do lucro contábil: O caso Parmalat Brasil. Revista de Economia e Administração, Porto Alegre, 50 ed, v. 12, n. 2, 2006.

COSTA, A. C. O.; TEIXEIRA, A. J. C.; NOSSA, V. Conservadorismo, accruals e qualidade dos lucros contábeis. In: XXVI EnANPAD, 2002, São Paulo. Anais... Curitiba: Associação Nacional dos Programas de Administração (ANPAD), 2002, CD-ROM.

COSTA, F. M.; LOPES, A. B.; COSTA, A. C. O. Conservadorismo em çinco países da América do Sul. Revista de Contabilidade \& Finanças, São Paulo, n. 41, maio-ago. 2006.

GUJARATI, D. Econometria Básica. 4. ed. Rio de Janeiro: Editora Campus, 2006.

LOPES, A. B. A relevância da informação contábil para o mercado de capitais: O modelo de Ohlson aplicado à BOVESPA. São Paulo: 2001. Tese (Doutorado em Ciências Contábeis) - Programa de Pós-Graduação em Controladoria e Contabilidade, Faculdade de Economia, Administração e Contabilidade, Universidade de São Paulo.

; MARTINS, E. Teoria da Contabilidade. 1. ed. São Paulo: Atlas, 2005.

OHLSON, J. Earnings, book values and dividends in equity valuation. Contemporary Accounting Research, Toronto, v. 11, n. 2, p. 661-687, 1995.

PAULO, E.; ANTUNES, M. T. P.; FORMIGONI, H. Estudo sobre o conservadorismo nas companhias abertas e fechadas brasileiras. In: XXX EnANPAD, 2006, Salvador. Anais..: Curitiba: ANPAD, 2006, CD-ROM.

RANGEL, L. L.; TEIXEIRA, A. J. C. O conservadorismo contábil e o valor de mercado. In: XXVII EnANPAD, 2003, Atibaia-SP. Anais... Curitiba: Associação Nacional dos Programas de Administração (ANPAD), 2003, CD-ROM.

SANTOS, L. S. R. Conservadorismo contábil e timeliness: evidências empíricas nos demonstrativos contábeis em US GAAP e BR GAAP das empresas brasileiras com ADRS negociadas na Bolsa de Nova Iorque. Vitória: 2006. Dissertação (Mestrado em Contabilidade) - Programa de Pós-Graduação em Ciências Contábeis da FUCAPE.

\section{NOTA - Endereço dos autores}

Universidade Federal do Ceará

Av. da Universidade, 2431

Fortaleza - CE

$60020-180$
Universidade de São Paulo

Faculdade de Economia, Administração e Contabilidade Departamento de Contabilidade e Atuária Av. Prof. Luciano Gualberto, 908 - prédio 3 - Cidade Universitária São Paulo - SP 05508-900 